\title{
A estética clariciana: possibilidades de leituras
}

\author{
The Clarician Aesthetics: Possibilities of Readings
}

\author{
Lucilene Machado Garcia Arf \\ Universidade Federal de Mato Grosso do Sul/Brasil \\ lucilene.arf@ufms.br \\ Recibido: diciembre de 2015. Aceptado: febrero de 2016
}

\begin{abstract}
Resumo: Este artigo é um recorte de um estudo mais amplo da recepção crítica da obra de Clarice Lispector na Espanha no período de 1973 a 1989, quando a instância de recepção crítica estava ainda longe de ser consolidada, mas que fornece um suporte notável para despertar o possível leitor para o potencial da escritora brasileira. A experiência estética da obra clariciana causa grande impacto nos diversos períodos e locais em que foi lida, embora alguns mais intensos que outros. Ao contrário da historicidade, a estética ajuda a compreender os distintos e variados mecanismos da constituição da tradição brasileira e da criação de projetos renovadores dentro da cultura nacional. Em outras palavras, a leitura estética de Lispector fora do Brasil contribui para o enriquecimento de sua fortuna crítica em território nacional.
\end{abstract}

Palavras-chaves: Recepção estética, Espanha, Clarice Lispector.

\begin{abstract}
This article is an excerpt from a broader study about the critical reception of Clarice Lispector's work in Spain in the period between 1973 and 1989 , in a moment when the level of critical reception was still far from being consolidated, but that provides an outstanding support in order to make any likely reader be interested in the potential of the Brazilian writer. The aesthetic experience of the Clarician work causes a great impact on different periods and locations where it was read, though with the different levels of intensity. Unlike historicity, aesthetics helps understand the different and varied mechanisms used to build up the Brazilian tradition and to implement renewing projects within the national culture. In other words, the aesthetic reading of Lispector outside Brazil contributes to the enrichment of her critical fortune in the Brazilian national territory.
\end{abstract}

Key-words: aesthetic reception, Spain, Clarice Lispector. 
Os textos críticos sobre Clarice chegaram à Espanha antes da própria literatura clariciana; o que podemos constatar por meio das produções periódicas no país ibérico. No ano de 1973, a Revista de cultura brasileña, editada pela embaixada do Brasil na Espanha e que hoje pode ser encontrada nos arquivos da hemeroteca da Fundación Cultural Hispano Brasileña, em Madrid, apresenta o artigo «Los nuevos novelistas brasileños (a propósito de Clarice Lispector)», escrito pela professora portuguesa Teresinha Alves Pereira.

Teresinha Pereira começa seu discurso falando do escritor Lucio Cardoso, em ascensão, como afirma ela, e que sugeriu o título da primeira obra de Clarice, Perto do coração selvagem, a partir da influência que este havia sofrido por parte de Joyce e outros escritores internacionais. Pereira fala dos valores da obra de Cardoso, submetidos a Joyce, como uma maneira de dar crédito a uma de suas seguidoras: Lispector. Fala da obra Crônica da casa assassinada que, entre outras coisas, remete às inovações técnicas usadas pelos novos escritores brasileiros, dentre os quais destaca a amiga de Cardoso: Lispector. A estrutura da Crônica da casa assassinada, tomada como «una de las mejores novelas brasileñas», segundo Pereira, é parecida com a estrutura de A maçã no escuro, em que futuro e passado se confundem. Em A casa, o protagonista escreve um diário que não respeita o tempo cronológico, em A maçã ocorre algo parecido: o crime de Martim já está consumado e ele se propõe a esquecer toda sua vida passada. Sua alma está destruída, a terra abandonada, toda a história terminada e então começa o romance.

O texto de Pereira relata que, depois de executar o crime, Martim adquire uma nova visão do mundo, porém ele crê que o mundo é que se transforma. Por meio do fluxo da consciência, Clarice faz com que o leitor aprenda com o personagem essa noção e passe a seguir sua história como cúmplice desse fato: o mundo se transforma ao gosto de Martim. O personagem começa por descobrir todas as coisas outra vez, como se elas estivessem aí, esperando, bastando que ele as reconhecesse para então começarem a existir.

Em sua crítica, Pereira defende a ideia de que Lúcio Cardoso e sua geração, do qual ele foi o experimentador, receberam da filosofia francesa o tema da desesperança, da sensação de que o homem está passando por uma perda nesse mundo trágico. Afirma que essa bebida da moda os brasileiros receberam da Europa e com ela embebedaram três gerações sucessivas de escritores. Também defende que em A Paixão segundo G. $H$. Lispector trata da busca da razão da vida. O personagem que simboliza o homem genérico apresenta o interior da consciência, de uma maneira simultânea, o sofrimento da angústia, da náusea, o sonho, a resignação e a renúncia. Acrescenta que:

O leitor das obras de Lucio Cardoso e de Clarice Lispector encontra-se frente a um personagem que sofre e comunica uma sensação de angústia «crescente», que chega à margem da cólera. Está ao ponto de cometer um crime contra si mesmo. Entretanto, este mesmo personagem pode também cometer um crime contra o outro, porém não se movimenta com ódio, e sim buscando a 
destruição do «ego» social e a liberação de um compromisso com o passado (Pereira 1973: 111) ${ }^{1}$.

Na leitura proposta por Pereira, a tragédia pessoal dos personagens de ambos os escritores está à margem da sociedade e precisa ser aceita como parte integrante da nova vida que se impõe, o que também ajuda na busca do mais íntimo no ser humano a fim de descobrir a si mesmo. O mágico mundo interior em que vivem os personagens provoca no leitor uma sensação, uma reação de dúvida, que não permanece porque a comunicação não se faz com o autor, mas sim com o personagem, em convivência muito íntima.

Para ela, a nova narrativa brasileira apresenta líricas semelhanças com a poesia, e esse é outro fator que faz pensar em Joyce como seu ascendente. Ou seja, a leitura da professora Teresinha condiciona o modelo positivo do Brasil a um conceito hegemônico de produção. O reconhecido escritor James Joyce, um dos mais influentes na Europa, detentor de um projeto literário experimental e inovador é quem motiva os escritores, entre estes, Clarice, embebedando-os por três gerações. A temática desesperança, herdada da França, segundo ela, retoma a representação do mundo como um poço de crueldade, o qual não é preciso compreender, senão sofrer. Além da crueldade, Pereira fala ainda da agressividade em um mundo onde o homem vive sempre aflito, com medo e angústia. Quanto à linguagem, ela considera que os dois escritores escrevem de forma um tanto simples. As palavras são selecionadas entre as do uso comum, diário, como se os autores tratassem de evitar a erudição e o lugar comum literário. O leitor poderá notar que é levado por meio da simplicidade e clareza a descobrir novos valores metafóricos usados para enriquecer cada vocábulo, destacando que a narrativa de Clarice está cheia de novas combinações, surpresas linguísticas e lirismo, baseado nas situações domésticas e na linguagem infantil.

Para concluir, a professora Teresinha Pereira considera que a nova narrativa brasileira não está fixada em uma só tendência, assim como não há chegado a ser o que é hoje por haver seguido uma tradição. E em Clarice Lispector, segundo ela, encontra-se muito mais que Joyce e Lúcio Cardoso. Porém,

Honestamente cremos que a influência de Joyce (de primeira ou de segunda mão), e a influência de Lúcio Cardoso, trabalhadas juntas e secretamente no laboratório mental de Martim, ou de G. H., ou de Lori (que são em última palavra, a consciência da autora), produziu os mais importantes romances metafísicos da literatura brasileira: Uma aprendizagem ou o livro dos prazeres, A maçã no escuro e A paixão segundo G. H. (Pereira 1973: 115)2.

1 El lector de las obras de Lucio Cardoso y de Clarice Lispector se encuentra al frente de un personaje que sufre y comunica una sensación de angustia «en crescendo», que llega al margen de la cólera. Está al punto de cometer un crimen en contra de sí mismo. Sin embargo, este mismo personaje puede también cometer un crimen en contra de otro, pero no acciona con odio, sino buscando la destrucción del «ego» social y la liberación de un compromiso con el pasado (Pereira 1973: 111).

2 Honestamente creemos que la influencia de Joyce (de primera o de segunda mano), y la influencia de Lucio Cardoso, laborando juntas y secretamente en el taller de la conciencia de 
Do ponto de vista da autora do artigo, a qualidade do texto clariciano está pré-definida dentro de uma concepção internacional que motiva os brasileiros a alcançá-la como uma forma de legitimá-los. Como se explorar a mesma temática fosse um procedimento para criar intelegibilidade para experiências do mundo, tanto as disponíveis como as possíveis reveladas pela literatura produzida nas metrópoles. Pereira fala, tendo como lócus enunciativo, um tempo histórico distante, 1973, quando a crítica a respeito de Clarice (e Lúcio Cardoso) eram bastantes escassas mesmo no Brasil, e o tema e o psicologismo sobrepunham a estética. Pereira não é espanhola, provavelmente tenha sido convidada pela revista a escrever para os espanhóis sobre a literatura brasileira e o que se vê é uma rancidez típica do sujeito «colonizador» que permeou a década citada e as posteriores e que, como se constata, tenta retirar o mérito do escritor brasileiro.

\section{CLARICE LISPECTOR, A FADA BOA}

Em 1975 a mesma Revista de Cultura brasileña anteriormente, produzida por profissionais espanhóis e brasileiros e editada pela embaixada do Brasil em Madrid, apresenta o texto cujo título leva o nome de Clarice. Esse artigo, assinado pelo brasileiro Hélio Póvoas, crítico literário, traz uma apresentação resumida da vida da escritora, fala de seu nascimento na Ucrânia e a vinda precoce para o Brasil, da residência em Recife, da mudança para o Rio de Janeiro e da sua convivência com escritores como Lúcio Cardoso, Adonias Filho e Otávio Faria. A partir daí, confronta-se com a obra de Clarice: começa pela primeira publicação a qual surpreendeu a crítica pela pouca idade da escritora em relação a seu domínio e flexibilidade com o idioma a par de um estilo originalíssimo que levava uma marca muito pessoal. Não se parecia a nenhum outro escritor brasileiro, a influência mais notória era da escritora Virgínia Woolf. Clarice introduzia nas letras brasileiras um lirismo que não vinha propriamente do tema, mas da estrutura hermética da ficção. A linguagem era a expressão elaborada, afligida, profundamente criativa de um romance de intensa vida interior. Em vez de buscar o realismo nas exterioridades, como se fazia então nos romances documentais brasileiros, Clarice submergia em busca dos conflitos existenciais do ser.

Póvoas complementa que a aparição de Lispector chamou muito a atenção do público leitor e passou a exercer grande influência sobre os jovens escritores, uma influência tão poderosa como dos contos de Katherine Mansfield ou do memorialismo de Proust. «Até hoje estamos presenciando o desenvolvimento de uma ‘família' Lispector» (Póvoas 1975: 12)․․

\footnotetext{
Martim, o de G. H., o de Lori (que son en última palabra, la conciencia de la autora), ha producido las más importantes novelas metafísicas de la literatura brasileña: Uma Aprendizagem ou O Livro dos Prazeres, A Maçã no Escuro y A Paixão segundo G. H. (Pereira 1973: 115, a autora manteve o nome das obras em portugués, ainda não haviam sido traduzidos para o espanhol).

3 «Hasta hoy estamos presenciando el desarrollo de una 'familia' Lispector» (Póvoas 1975: 12).
} 
Para o crítico, de todos os romances de Clarice (até então), o que mais se destaca é A maçã no escuro, cuja escritora encontra-se em plena maturidade e na fase mais ambiciosa de sua criação literária. Assegura ele:

É um dos mais importantes títulos da obra de Clarice Lispector e, sem dúvida, o mais límpido, brilhante e dialético de seus romances. Por uma razão muito simples: a autora conseguiu fundir, em um modelo perfeito, ficção e prosa. $\mathrm{O}$ exercício da palavra lúcida não substitui a estrutura da ficção, nem esta predomina de modo que imprima ao romance a forma de documento realista. Romance lírico, romance de ideias, no qual os personagens se projetam, imaterializando-se, interiorizando-se em seus próprios conflitos, de tal maneira que passam a existir simbolicamente (Póvoas 1975: 13).

$\mathrm{Se}$, como romancista, Clarice surpreendeu, o mesmo ocorreu como contista. Póvoas cita a opinião de vários especialistas em seu texto, como Astrid Cabral e Adonias Filho que, na época, escreveram várias críticas positivas à obra clariciana. Reconhece que a prosa de Clarice tem uma densidade diáfana, uma transparência de cristal nobre além de uma compaixão pelos humildes. A arte clariciana toca o núcleo das emoções legítimas, sem o apoio das mãos, apenas roçando com a frase inteligente e sensível, algo singular no panorama brasileiro, que na fugacidade do conto encontra oportunidade de exercer-se com plenitude.

$\mathrm{O}$ autor do artigo finaliza declarando que Lispector surpreende em suas sequências dinâmicas, no instante exato das revelações. Que a arte de expor a consciência e desvelar os corações deve ter uma origem prodigiosa e Clarice, em nossa literatura, é a fada boa que enfeitiça as palavras com o toque de sua varinha mágica.

Póvoas, fala da produção inovadora de Clarice, seu hermetismo, sua capacidade de manipular o idioma e o lirismo como marcas muito pessoal e, cita Virgínia Woolf como sua principal influência. O crítico não faz um diagnóstico do projeto literário de Clarice, nem apresenta o caráter verdadeiro ou falacioso dessa renovação, fala apenas desse «novo» e original dotado de positividade intrínseca que igualaria a brasileira aos escritores universais. No número 37 da Revista de cultura brasileña, de dezembro de 1974, e republicado em junho de 1997, Póvoas assinala no artigo «El moderno cuento brasileño» em que repete ser a prosa de Clarice de uma densidade diáfana, uma transparência de cristal nobre, uma compaixão pelos humildes que recorda Katherine Mansfield (p. 117). No mesmo texto, ele critica os imitadores de Mansfield usando o termo que Álvaro Lins denominaria de «a família Mansfield brasileira» (p. 114).

${ }^{4}$ Es uno de los más importantes títulos en la obra de Clarice Lispector y, si duda, la más límpida, brillante y dialéctica de sus novelas. Por una razón muy sencilla: la autora logró fundir, en modelo perfecto, ficción y prosa. El ejercicio de la palabra lúcida no sustituye la estructura de la ficción, ni ésta predomina de modo que imprima a la novela la forma de documento realista. Novela lírica, novela de ideas, en la cual los personajes se proyectan, inmaterializándose, interiorizándose en sus propios conflictos, de tal manera que pasan a existir simbólicamente (Póvoas 1975: 13). 
Segundo Póvoas, tivemos bons e falsos mansfieldeanos. A tradução de Bliss influenciou muitos narradores novos:

Em geral, tratava-se de uma influência literária mal assimilada, produzindo imitações insípidas. $\mathrm{O}$ que na suave Katherine, mais que uma forma de escrever, era algo de seu temperamento, uma morbidez insinuada pela doença, uma ternura natural pelas vidas das senhoras Parker e outros seres humildes, transformou-se, entre nós, em um estilo geral de narrar (Póvoas, 1997: 114) 5 .

Embora Clarice demonstre ter a mesma compaixão pelos humildes de que trata Mansfield, os leitores do texto de Póvoas, que ainda não conheciam a narrativa da brasileira, foram levados a pensar, pelo menos a desconfiar, que Clarice pertence à categoria dos bons imitadores e consegue «tocar o núcleo das emoções legítimas, sem forçar a mão, apenas roçando-a com a frase lúcida» (p. 118). E nós, desconfiamos que o crítico, também brasileiro, profere um discurso típico do colonizado que carrega o complexo de estar em condição sempre inferior à metrópole, reforçando o estigma da subalternidade que por muitos anos esteve intrínseca à condição de sul-americano.

\section{LITERATURA E ISOLAMENTO}

Outro texto com teor crítico publicado sobre a obra de Clarice, antes que a obra fosse lida na Espanha, encontra-se, na revista Triunfo, uma revista que circulou nos anos de 1962 a 1982 e era uma das revistas de circulação mais importantes da época, que mantinha uma coluna para tratar das artes e literatura. Nessa coluna foi publicado em setembro de 1977, após o lançamento do primeiro livro de Clarice na Espanha, Cerca del corazón salvaje, o artigo «Literatura y aislamiento». Ilustra o texto, o mesmo retrato de Clarice publicado no ano anterior, 1976, por ocasião de uma entrevista. A autora Renata Rocco-Cuzzi alude à literatura como espaço do qual emergem, por um lado, os problemas inerentes à mesma como prática específica. Porém, também, por outro, um lugar onde se reflete uma série de questões que a excedem.

Com estas palavras Rocco-Cuzzi pontua os elementos básicos de Cerca del corazón salvaje, um romance inaugurador no Brasil, de uma corrente que conta entre seus traços característicos a preocupação pela forma, transitando na vereda oposta ao realismo, convertido em objeto sustentador de uma realidade própria e um comportamento individual desligado de todo o contexto social.

Um terceiro núcleo de interesse, segundo a autora do texto, trabalhado na obra da brasileira é o tratamento dado à mulher. Uma linha que questiona o

5 En general, se trataba de una influencia literaria mal asimilada, produciendo imitaciones insípidas. Lo que, en la suave Katherine, más que una forma de escribir, era un rasgo de su temperamento, una morbidez insinuada por la enfermedad, una ternura natural por las vidas de las ancianas Parker y otros seres humildes, se transformó entre nosotros en un estilo general de narrar (Póvoas, 1997: 114). 
modelo tradicional e trata de uma literatura produzida por uma mulher que elege como personagem central a outra: a mulher dona da voz e a sua parte oposta; no caso, Joana e Lídia. Na sequência, Rocco-Cuzzi cita partes do livro e do esquema entre os personagens que possuem polos diversos entre si, definindo a obra como uma novela de aprendizagem. Mais que isso, ela usa o termo «tipicamente adolescente», caracterizando-se por sua constante busca, dúvida e inclusive meditação filosófica. Segundo ela, trata-se de uma aprendizagem singular, o que se supõe aprender a viver em solidão. Sobre a estrutura, ela adverte tratar de uma série de círculos concêntricos, representado pela figura de Joana, fechando-se em si mesma, incapacitada que é para vincular-se com o mundo ou com os outros.

Um fato intriga a autora do artigo é a realidade brasileira aludida no texto sempre como um elemento a mais. Não se trata de resgatar folclore ou o populismo literário, mas sim de definir o signo da obra de Lispector em função de seu contexto social. Após questionar vários fatos sobre o livro ter sido produzido no Brasil, a própria autora reconhece que para responder as perguntas seria necessário, entre outras coisas, ter elaborado uma explicação do fenômeno das vanguardas e sua incidência na modificação do statu quo, e da evolução desse fenồmeno em um país subdesenvolvido. Ela questiona: «Que significa, no Brasil de 1944, publicar um livro cujo título foi extraído de um texto de James Joyce? E que, pode ser caracterizada dentro da literatura brasileira como uma precursora da renovação formal e fundadora da corrente intimista?» (RoccoCuzzi, 1977) ${ }^{6}$.

O comentário de Renata Rocco-Cuzi é um tanto depreciativo e revela um leitor que se sente em condição superior. Talvez sirva como exemplo do que implica a recepção quando está em jogo a diferença entre passado e futuro ou entre culturas divergentes. Embora a leitura tenha sido feita nos anos setenta, a interpretação já reproduziu o que seria o efeito estético. Em vez de decifrar o sentido do texto, a autora-leitora tenta evidenciar o potencial de sentidos proporcionado por ele. Não recorre a nenhuma referência para se justificar, seu reconhecimento se dá por meio da experiência leitora em relação ao caráter estético. Inclusive, adverte no inicio que há algumas questões refletidas pela literatura que excedem o próprio espaço da literatura. Evidentemente ela está se referindo à Clarice e ao fato de tal fenômeno estar ocorrendo no Brasil, que não é o lugar para a evolução literária. As palavras usadas por Rocco-Cuzi, ou o seu parecer sobre o livro Cerca del corazón salvaje são anacrônicos, considerando que a crítica foi feita nos anos setenta, época em que o país vivia em um regime militar cujas circunstâncias afetavam sintomaticamente a arte. Diante desse fato torna-se razoável considerar que a leitura da profissional espanhola estava condicionada pelos fatores políticos culturais inerentes ao contexto mundial de então, ou seja, ela estava colocada dentro do seu horizonte de compreensão a constituir um sentido para o texto. Entretanto, a jornalista deixa transparecer visível preconceito

\footnotetext{
${ }^{6}$ ¿Qué significa que en Brasil de 1944 se publique un libro cuyo título ha sido extraído de un texto de James Joyce? Y qué, poder ser caracterizado dentro de la literatura brasileña como una precursora de la renovación formal y fundadora de la corriente intimista? (Rocco-Cuzzi, 1977, texto na íntegra nos anexos deste trabalho).
} 
em relação ao local onde a literatura é produzida. Rocco-Cuzzi fala de um lugar que é a Europa, e não a Espanha. Há de se recordar que em 1977, a Espanha vivia uma crise na produção de arte. Os escritores que despontaram nesta época foram inexpressivos, considerando o franquismo, termo empregado para se referir a ideologia política e movimento social de caráter fascista que sustentou o regime ditatorial liderado pelo general Francisco Franco que prevaleceu até sua morte em 1975. Partindo deste princípio, é possível que seu preconceito seja uma forma de negar seu próprio lócus enunciativo. Iser assinala que,

Os seres humanos estão tão enredados em seu entorno, tão formados e condicionados pelo que prolongam de si mesmo, e tão desafiados pelo mesmo hábito que construíram para sobreviver e manter-se, que de maneira inevitável o interesse pela cultura surge em proporção ao declínio de uma opinião uniforme da natureza humana (ISER, 2005: 178).

Para Iser, esse tipo de percepção significa o ponto de partida de uma espiral retroativa entre os seres humanos e a cultura. A autora deixa transparecer que no exercício de preenchimento dos espaços vazios e das indeterminações produzidas pelo texto, previstos por Iser, surgem novas variáveis e novas perspectivas que extrapolam e abalam os valores de sua experiência estética, de modo a apresentar uma crítica frágil e frouxa com demonstrações de uma orgulhosa ignorância.

\section{CLARICE LISPECTOR, QUEM ERA?}

Em 24 de dezembro de 1977, a mesma revista Triunfo volta a falar de Clarice. Dessa vez esclarecendo a morte da escritora, o que teria ocorrido recentemente e, por engano, a imprensa espanhola noticiou que a escritora teria 80 anos.

A matéria circulada, ou seja, sem assinatura de um autor específico, o que sugere ser a opinião da revista em si, ataca duramente a crítica literária espanhola por não ter se ocupado da obra da escritora brasileira Clarice Lispector. A notícia da morte da escritora pouco significou para os leitores espanhóis interessados pelas letras, de modo que a revista volta a comentar a matéria publicada anteriormente (três meses) por Renata Rocco-Cuzzi e a entrevista, publicada no ano anterior, realizada pela jornalista Maria Esther Gilio.

A revista Triunfo publica, pela terceira vez, a mesma foto de Clarice ao lado de uma estante de livros, com feição séria e grandes olhos exóticos, além de voltar a valorar a obra Cerca Del corazón salvaje, publicada na Espanha pela editora Alfaguara, que inaugura no Brasil uma corrente, apontando como traços mais característicos a preocupação com a forma. Ainda, na sequência do texto, Clarice é comparada a Guimarães Rosa e a Murillo Rubião.

\section{A LITERATURA SECA DE CLARICE LISPECTOR}

Dos anos setenta, saltamos para a década de oitenta, especificamente para os anos finais. Parece pertinente abordar a produção crítica espanhola sobre 
Clarice Lispector usando como referência a cronologia, uma maneira também de homenagear os pioneiros na divulgação da obra da brasileira no país mediterrâneo. Uma destas pioneiras é a tradutora, também escritora, Cristina Peri Rossi, que a título de prefácio escreve na primeira edição de Silencio (tradução de Onde estiveste de noite, 1988) «Prólogo a la edición castellana». Para isso, Cristina recorre à crítica brasileira para constatar o que esta pensa sobre a produção clariciana, mas não se fixa apenas na crítica. Atem-se mais ao papel de Clarice na sociedade do que propriamente à leitura de suas obras. O texto aborda a importância da escritora na modernização da literatura brasileira com predomínio pitoresco, localista, cujas narrativas descrevem uma realidade miserável, complexa e permeada por contrastes. Rossi assinala que, em quase toda a literatura brasileira anterior, o tema fundamental dos romances era a paisagem vasta e desoladora, o quase desértico sertão e os subúrbios miseráveis e superpovoados das grandes cidades. Uma temática tão onipotente que invadiu a literatura brasileira com uma força avassaladora, a exemplo de Vidas secas e Macunaíma. Clarice, segundo ela, supera essa influência ambiental com um aberto despudor produzindo contos e romances urbanos. A voz da narradora é sempre a de uma mulher urbana, contemporânea, atenta ao seu próprio olhar, já que para Clarice a veracidade está na profundidade do olhar.

Peri Rossi (1988:10) afirma ser curioso que a grande renovadora da literatura brasileira faça uma confissão (no livro em que prefacia) não muito comum e destaca a frase insólita: «digo o que tenho de dizer, sem literatura». A declaração, sem despojamento, na opinião da prefaciadora, relaciona-se, no entanto, com essa pretensão de verdade, de percepção e com o estilo de Lispector. Se a literatura é metáfora e, portanto, polivalente, múltipla de imagens, o esforço de veracidade passa por outra forma do literário, aparentemente pela renúncia dessa interpretação do poético. O que significa escrever com o olhar, sem adornos, em busca do essencial que prescinde justamente do metafórico e da proliferação de imagens, para que a literatura seja uma investigação do interior e não espelhos polivalentes. Usa como exemplo o conto «Seco estudios de caballos», que melhor define a obra e o estilo de Clarice: seco. Porém a sequidão a que se refere não é um limitador e sim uma virtude por meio da qual essa renúncia às pompas da imagem e leva à profundidade da percepção. A falta de literatura de Clarice se converte em sua própria literatura.

Seguindo o raciocínio apresentado por Cristina Peri Rossi, a obra de Clarice está filiada aos escritores surrealistas, além de James Joyce e Virginia Woolf, o que justificaria as numerosas intervenções da brasileira nas narrativas dos contos. Para Rossi, poucas vezes os contos têm verdadeira autonomia, não são realidades independentes, o laço, a conexão com sua autora estão sempre presentes, a partir de suas invenções. Acrescenta ela que a autora intervém para corrigir, intervém para confessar, intervém para falar com os personagens, como se as histórias e ela, que as vê e as escreve, não pudessem se separar ou desprender-se. Reforça que a fantasia da compenetração uterina justifica o fato de ser a autora mulher, e talvez, como em poucas vezes, somente uma mulher. Uma mulher que pode estar tão entranhada em si mesma, ao seu olhar, ao seu pretexto que esta união umbilical torna-se indestrutível. 
Peri-Rossi declara ser possível verificar como Clarice luta com as dificuldades de escrever, sem que oculte seu mau-humor ou sua impotência. Outras vezes, seus contos se mesclam tanto com o processo de escritura que terminam por ser um relato de si mesma. Recorda, ainda, que alguns textos dificilmente podem ser catalogados como contos, são fragmentos, porém que contém toda a força poética de uma visão, de uma contemplação íntima e rigorosa.

A leitura de Cristina Peri Rossi da obra Silencio (Donde estivestes de noite?) é notadamente balizada pela ideologia feminista, segmento em que a mesma é militante, quando embasa sua narrativa em uma fantasia de compenetração uterina ou quando fala de uma mulher entranhada em si mesma e com o texto, cujo cordão umbilical torna-se indestrutível. A prefaciadora mescla personagens, narrador e autor. Fala de Clarice como se falasse das mulheres que são tratadas nos contos. O perfil que constrói da escritora, a partir de sua escritura é para tentar estabelecer relações entre autor e obra, entre perspectivas teóricas, estéticas e históricas, mas não consegue realizar tal tarefa sem evitar eventuais depreciações. Ela foge do rigor analítico e interpretativo e julga a partir de uma concepção superficial, como dizer que Clarice luta contra as dificuldades de escrever sem ocultar o mau-humor ou a impotência.

A uruguaia radicada na Espanha não deixa também de filiar Clarice aos europeus James Joyce, Virginia Woolf e os surrealistas. Não comprova as relações, tampouco se aprofunda ou discute as consequências dessa filiação. Sua interpretação parece ser resultado de circunstâncias fortuitas e vagas, embora de início, ela tenta sistematizá-la na história brasileira. O fato de ser sul-americana poderia contribuir com a leitura, já que compartilhamos alguns repertórios coletivos que poderiam ganhar contornos peculiares quando colocados na situação concreta de fruidor-intérprete. Poderia oferecer ao leitor de Silencio um amplo espaço de mobilidade e de atuação, porém, Rossi vai falar de um lugar bem longe dessa intenção.

\section{CLARICE LISPECTOR: O ÍNTIMO SUSPIRO DA VIDA}

No artigo «Clarice Lispector: El íntimo suspiro de la vida» (1989), Antonio Maura Barandiarán faz um apanhado sobre seis das principais obras (romances) de Clarice, inclusive obras ainda não publicadas no país, evidenciando o potencial estético do conjunto, de forma a estimular a leitura das obras em questão. Ele salienta:

Acredito que esta primeira amostra permita aproximar-se de um dos espíritos mais fascinante, mais livres e mais vitais da literatura de nosso século. Ler Clarice Lispector é como empreender uma viagem, e aconselho, se tentarem, que façam antes suas malas: não será tão fácil regressar (1989: 268)7.

${ }^{7}$ Confío que esta primera entrega permita aproximarse a uno de los espíritus más fascinantes, más libres y más vitales de la literatura de nuestro siglo. Leer a Clarice Lispector es como emprender un viaje, y le aconsejo, si lo intentan, que hagan antes sus maletas: no les será tan fácil regresar (1989: 268). 
O autor inicia discorrendo sobre a estrutura dos textos claricianos embasados nas sensações e sentimentos, sugerindo, à primeira vista, que a verdadeira temática do texto é um jogo oscilante e atrevido do pensamento, o que seria o segredo da escritora nascida na Ucrânia, mas com profunda sensibilidade brasileira.

Seguindo a cronologia das publicações no Brasil, Antonio Maura começa seu estudo com a obra Perto do coração selvagem, cujo objetivo não é apenas conhecer a alma humana, mas o selvagem coração da vida. Assim, passa a narrar o brotar de uma mulher e sua abertura para a vida como uma flor esplêndida. E também seu fracasso, sua incompreensão, da qual é objeto Joana, a protagonista. Depois de fracassar em todas as suas tentativas de justificar-se junto aos demais, Joana se vê obrigada a refugiar-se em uma viagem interior, onde não existem fronteiras e o ser se desenvolverá livre e pleno, pois navega por seu próprio instrumento. A partir de então, cada um de seus romances, segundo o autor, será o relato de uma experiência interior, por um périplo pelas paisagens da consciência.

Sobre O lustre, o segundo romance de Lispector, Maura fala que Clarice tenta dar as chaves estruturais do que deve ser um texto narrativo, sem, porém, conseguir. Trata também da história de uma mulher de nome Virginia e do desenvolvimento de seus sentimentos e sensações entre o aviso de morte em plena adolescência até o momento em que esta se produz. Nesse intervalo, a narradora tenta responder a um sem número de perguntas sobre o sentido da vida e da morte.

No entanto, segundo o professor, $O$ lustre é um romance, de certa forma, malogrado, em que a autora não consegue ajustar as estruturas narrativas às temáticas. Clarice quer escrever um romance e aceitar as normas que este gênero exige, porém se sente incapaz e se choca contra elas como uma borboleta capturada. Consegue paisagens belíssimas quando adquire espaço suficiente para voar, porém choca-se com suas próprias cercas. Para ele, Clarice é extremamente livre e não pode suportar nenhum tipo de normas, nem mesmo as suas.

Ao contrário, A maçã no escuro é considerada por Maura uma obra redonda, além de trazer pela primeira vez um protagonista homem que percorre o caminho que vai desde o assassinato de sua mulher até o momento em que a polícia o recolhe: um trajeto fundamentalmente filosófico e religioso. Um mesmo argumento permite duas reflexões: sobre a vida e sobre a morte. Para o crítico, Clarice consegue realizar um livro de muita beleza, que em seu princípio pode parecer complexo; no entanto, torna-se transparente e permite à sua autora todo um alarde de sua sensibilidade e de sua certeira intuição. Com A maçã no escuro, Clarice se faz dona de todos os recursos narrativos e dramáticos de que um romance necessita para converter-se em uma obra de arte, porém a força fundamental do livro é o poder da palavra.

Em A paixão segundo G. H., Antonio Maura Barandiarán segue permeando o mundo das sensações e sentimentos. Desta vez, um pouco mais dolorosos, a descida do ser humano ao núcleo onde reside o impulso vital. Há todo um caminho de iniciação ascética que nos leva até o ponto incomensurável e vazio do silêncio. A protagonista, também narradora, se vê despojada de todos os atributos espaço-temporais que lhe davam consistência como mulher e como ser 
humano, também enfrentando a nudez intrínseca do animal. A narrativa é o doloroso rito da protagonista que se funde ao significado do inseto arcaico, cuja capacidade de sobreviver é superior a do homem. Trata-se de um dos poucos bichos capazes de suportar uma destruição nuclear. GH se encontra diante dessa essência da vida, deste rio subterrâneo que flui desde a origem dos tempos até ao futuro desconhecido. Mas não é apenas encontrar esse leito fluvial, sim de ir mais longe, de chegar até o âmbito central do núcleo, o centro da semente, para submergir-se, perder nas marés dos olhos, dos olhos de barata que olham frente a frente a narradora.

Em Uma aprendizagem ou livro dos prazeres, a protagonista Lori, segundo a leitura de Antonio Maura, já conhecedora da experiência de G. H., decide amar fisicamente um professor de filosofia, mas somente quando se sentir preparada para isso. A história é também uma iniciação, mas ao contrário de G. H., ao se despojar do humano, tenta encontrar a raiz vivente. Uma aprendizagem constitui-se num conjunto de anotações que vão desde pequenas urgências cotidianas, anotações de diários, pequenos poemas, palavras de canções que impressionavam a protagonista até pensamentos e sentimentos timidamente expostos. Porque não se trata de conquistar Ulisses ou apaixonar-se por ele, mas sim de refazer-se como mulher para alcançar o amor de um homem. Essa viagem de ida e volta à raiz do vivente, faz de Lispector uma mulher sábia em todo o significado da palavra, uma mulher que teve a oportunidade de conhecer as mais insólitas vivências: rodou pelo despenhadeiro da essência e voltou a sua forma humana.

Em Água viva, livro de fascinante beleza, Maura segue explorando, com o mesmo discurso poético, embora de cunho ensaísta, o exercício de Lispector em captar o momento, pois a essência da vida é o brotar contínuo do instante, um contínuo refazer-se e palpitar. O pensamento discorrido no livro é livre, segundo ele, é volátil, certeiro e sábio; semelhante ao rastro luminoso de uma borboleta. Fala de flores com a sabedoria de uma mulher, e do mais íntimo sentimento dos animais como se já houvesse habitado dentro de seus corpos. Fala dos armários, dos portais e das grutas, dos espelhos como cascatas de reflexos ou vazios cristalizados, dos perfumes, dos sons, tonalidades e sensações da pele, dos estados anímicos e da eternidade. Enfim, da palavra, do pensamento que, como um gnomo, a ocupou e fez dela a sua casa. Água viva é um magnífico poema em prosa, um adágio cantável, um friso delicadíssimo em branco e ocre. Para Antonio Maura, o livro é uma obra de arte redonda e bonita que se deve ler em silêncio para ser capaz de captar todas as suas ressonâncias.

O trabalho de Maura determina o contexto espanhol como um novo espaço de subjetividade de leitura e demonstra, ao mesmo tempo, que o conjunto de afinidades a serem eleitas para a obra de Lispector pode ser alargado amplamente e que as interferências críticas podem variar segundo os mecanismos que identificam determinada época e determinado local, ampliando ou mesmo restringindo o campo de possibilidades de recepção. A obra é a ponte que liga temporalidades e lugares diferentes, além de permitir diálogos entre ambas. Posteriormente, Maura produziu outras leituras críticas mediante as reacomodações e ajustes da obra clariciana no contexto espanhol. Há sempre uma nova 
percepção do crítico espanhol em relação ao texto, embora estes estejam situados dentro de um conjunto regrado e limitado quando diz respeito a chaves interpretativas, o que, na concepção dele, Clarice não oferece.

$\mathrm{O}$ destino de todo livro é misterioso, sobretudo para seu autor. Creio que Clarice nunca imaginou uma comunidade de leitores espanhóis que, de maneira individual e em circunstâncias muito distintas de nós brasileiros, teriam experiências semelhantes às nossas, compartilhariam dos mesmos ritos de iniciação, como o de ler antes os contos, viveriam as mesmas epifanias, manifestar-se-iam efusivamente em encontros e escreveriam apaixonadamente sobre sua obra, semelhantemente ao que ocorre no Brasil. Isso permite afirmar que na medida em que a obra clariciana vai se tornando universal, os leitores também. O escritor argentino/canadense Alberto Manguel escreveu em Una historia de la lectu$r a$ que: «a verdade é que nosso poder como leitores é universal e é universalmente temido»(2006: 15) ${ }^{8}$.

No entanto, literatura brasileira produzida nas mesmas décadas que Clarice, encontrava-se profundamente marcada pelo documentarismo social, pelo regionalismo da década de 30, uma literatura de sólidos conteúdos e extremamente realista em sua forma, daí que a narrativa lírica, abstrata, cheia de matizes e mistérios era inconcebível. Tão inconcebível quanto a própria Clarice, uma «estrangeira» que faz sua estreia na literatura emprestando sua voz a cada um de seus personagens. Uma voz única, estranha e singular que irá percorrer o longo caminho traçado desde Perto do coração selvagem até Um sopro de vida, livro póstumo.

Essa rejeição da crítica não ocorre na Espanha, já que a recepção de Clarice no país se deu muitos anos depois. Comprova-se que a leitura mais comprometida e intensa da obra clariciana se dá nos anos 90 , quando um público relativamente grande passa a ter acesso à obra da brasileira. Durante esse período, vários acontecimentos históricos, sociais, políticos modificaram o curso da arte, da teoria, ciência, de forma que houve uma evolução cultural que permitiu ao crítico espanhol uma recepção muito mais fluída, muito mais aproveitada que as recepções brasileiras dos anos 40 até 80 . Críticos muito mais dispostos a procurar pistas, a investir na tarefa de interpretar uma desordem interior transformada em literatura ou um conjunto de frases arrebanhadas do vazio profundo, do que foi meramente percebido no escuro doloroso e confuso, de maneira a conseguir plasmar alguma sorte de epifania levada às últimas consequências.

\section{BIBLIOGRAFÍA}

Arf, L. Machado Garcia (2013) «Entre abanicos e castanholas»: recepção de Clarice Lispector na Espanha. Tese de doutoramento: Universidade Estadual Paulista, Instituto de Biociências, Letras e Ciências Exatas, São José do Rio Preto.

${ }^{8}$ La verdad es que nuestro poder como lectores es universal y es universalmente temido (2006: 15). 
Lispector C. (2005) Cerca del corazón salvaje. Trad. Basilio Losada Castro. Madrid, Edições Siruela S. A.

Gilio, M. E. (1976) «Tristes tópicos: con Clarice Lispector en el Rio». Revista Triunfo, ano XXX, n. ${ }^{\circ}$ 697, 52, Madrid, junho de 1976. 'http://hdl.handle. net/10366/64966'.

Iser, W. (1996) O ato da leitura: uma teoria do efeito estético. São Paulo, Ed. 34, 1996 a vol. I.

Iser, W. (1996) O ato da leitura: uma teoria do efeito estético, São Paulo, Ed. 34, $1996 b$ vol. II.

Maura, A. (1989) «Clarice Lispector, el íntimo suspiro de la vida». Cuadernos Hispanoamericanos, núm. 469-470 julio-agosto, pp. 264-268

Manguel, A. (2006) Una historia de La lectura. Trad. Eduardo Hojman. Barcelona-ES, Lumen.

Pereira, T. Alves (1973) «Nuevos escritores brasileños: a propósito de Clarice Lispector». Revista de cultura brasileña, n. ${ }^{\circ}$ 35, Madrid: Embajada del Brasil en España, maio. Disponível também em:

'http://hemeroteca.fundacionhispanobrasilena.es/files/FICHERO948'. Acessado em 17/09/2010.

Póvoas, H. (1975) «Clarice Lispector». Revista de cultura brasileña, n. ${ }^{\circ} 35$, Madrid, Embajada del Brasil en España.

Rossi, C. Peri (1995) «Prólogo». Silencio. Traducción de Cristina Peri Rossi. Barcelona, Grijalbo/Mondadori.

Rocco-Cuzzi, R. (1977) «Literatura y aislamiento». Revista Triunfo. Año XXXII, n. 775 (3 dic. 1977), p 53. 'http://hdl.handle.net/10366/68183 Acessado em 18/08/2010'. 